\title{
Effects of Maturation Conditions on Spindle Morphology in Porcine MII Oocytes
}

\author{
Satoshi UENO ${ }^{1)}$, Mayuko KUROME ${ }^{1)}$, Hideto UEDA ${ }^{1)}$, Ryo TOMII'), \\ Katsumi HIRUMA ${ }^{1}$, and Hiroshi NAGASHIMA ${ }^{1)}$ \\ 1) Laboratory of Developmental Engineering, Department of Life Science, School of Agriculture, \\ Meiji University, 1-1-1 Higashimita, Kawasaki, 214-8571, Japan
}

\begin{abstract}
Incomplete cytoplasmic maturation of in vitro matured (IVM) oocytes has been known to cause microtubule and microfilament alterations, which may result in abnormal pronuclear formation and failed embryonic development. We examined the influences of maturation conditions on meiotic spindle morphology at metaphase of meiosis II (MII) in porcine oocytes. Porcine oocytes were matured under various conditions, i.e., in vitro or in vivo, with different amounts of cumulus cells, with or without hormonal supplements, and with various exposure durations to the hormones, to examine the effects on spindle morphology in MII oocytes by immunofluorescence under confocal laser microscopy. Interpolar spindle length $(\mu \mathrm{m})$ and spindle area $\left(\mu \mathrm{m}^{2}\right)$ were compared among these maturation conditions. The spindle length was significantly shorter in IVM oocytes compared to those matured in vivo. Oocytes collected from cumulus oocyte complexes (COCs), which were poor in cumulus cells, showed smaller spindle areas than those from cumulus-rich COCs. The spindle length and area were both significantly reduced in oocytes grown without hormonal supplements. When oocytes were grown with hormonal supplements for either 6 or 22 hours for the first half of culture, there was no difference in the spindle morphology between these oocytes. These results suggested that maturation conditions significantly influence morphogenesis of MII spindles in porcine oocytes. Oocytes matured in poor conditions were more likely to have a shorter spindle length (long axis) and smaller spindle areas.
\end{abstract}

Key words: Pig, Oocyte, IVM, Spindle, Maturation

(J. Reprod. Dev. 51: 405-410, 2005)

R ecently, transgenic pigs have been recognized as an essential animal for biological and medical applications [1]. For example, transgenic pigs have been used for production of biologically active compounds and as human disease models [2, $3]$, and genetically modified cloning of pigs has been attempted to generate organ grafts for xenotransplantation [4].

Production of genetically modified pigs requires advanced reproductive technologies, especially for

Accepted for publication: March 1, 2005

Published online: April 5, 2005

Correspondence: S. Ueno (e-mail: cf50405@isc.meiji.ac.jp) micromanupulation of oocytes. Traditionally, transgenic pigs have been produced using in vivo derived eggs, but the use of in vitro matured (IVM) oocytes has become mainstream in recent years because of the substantial cost and workload involved in obtaining a sufficient number of in vivo derived eggs [5].

The developmental potential of porcine IVM oocytes, however, is not as high as that of in vivo derived oocytes; the major problem stems from improper cytoplasmic maturation of IVM oocytes [6]. It has been found that incomplete cytoplasmic maturation of IVM oocytes often contains abnormal 
microtubules (MTs) and microfilaments, which in turn cause abnormal pronuclear formation and defective embryonic development [7]. The abnormality in MTs profoundly influences formation of the meiotic spindle, a dynamic assembly of MTs [8], and it is often associated with abnormal chromosome segregation after fertilization and reduced developmental rates of embryos as a consequence [9]. Thus, in mice and humans, the spindle morphology at metaphase of meiosis II (MII) has been used as an index of the cytoplasmic integrity of oocytes [10,11]. Further, the conditions for eggs, such as maturation in vivo or in vitro, superovulation induction, and aging affect the MII spindle morphology in mice [12, 13].

In this study, we examined the impact of variations in oocyte maturation conditions on spindle morphogenesis at MII in porcine oocytes to determine whether the MII spindle morphology can be used to evaluate the developmental competence of oocytes.

\section{Materials and Method}

\section{Chemicals}

Unless otherwise indicated chemicals, were obtained from Sigma-Aldrich Corporation (St. Louis, MO, USA).

\section{Collection of ovulated oocytes}

Crossbred (Large White/Landrace $\times$ Duroc) prepubertal gilts weighing between 100 and $105 \mathrm{~kg}$ were used as donors of oocytes. Gilts were treated with a single IM injection of 1500 IU eCG (Teikoku Zouki Co., Tokyo, Japan). Ovulation was induced by an IM injection of 1500 IU hCG (Teikoku Zouki) given $71 \mathrm{~h}$ after the first injection of eCG. Oocytes were collected by retrograde flushing of the oviduct under general anesthesia 47 to $50 \mathrm{~h}$ after the hCG injection.

\section{In vitro maturation of oocytes}

Ovaries were recovered from gilts at a local slaughterhouse and transported to the laboratory in Dulbecco's phosphate-buffered saline (PBS, Nissui Pharmaceutical, Tokyo, Japan) containing $0.1 \%$ (w/ v) polyvinylalcohol (PVA), $75 \mu \mathrm{g} / \mathrm{ml}$ penicillin $\mathrm{G}$, and $50 \mu \mathrm{g} / \mathrm{ml}$ streptomycin.

Cumulus oocyte complexes (COCs) were aspirated from follicles (diameter 3-6 $\mathrm{mm}$ ) using a 20-gauge needle attached to a $10-\mathrm{ml}$ disposable syringe and were washed twice with Hepesbuffered Tyrode's medium containing $0.3 \%(\mathrm{w} / \mathrm{v})$ polyvinylpyrrolidone medium (Hepes-TL-PVP). Groups of 20-25 COCs were cultured for $44 \mathrm{~h}$ in a $100 \mu$ droplet of NCSU23 medium [14] supplemented with $0.6 \mathrm{mM}$ cysteine, $10 \mathrm{ng} / \mathrm{ml}$ epidermal growth factor, and $10 \%(\mathrm{v} / \mathrm{v})$ porcine follicular fluid, and covered with paraffin oil in a 35 mm petri dish (Falcon no. 1008, Becton Dickinson Labware, Franklin Lakes, NJ, USA) at $38.5 \mathrm{C}$ under $5 \% \mathrm{CO}_{2}$ in air. Hormonal supplements of $10 \mathrm{IU} / \mathrm{ml}$ eCG and $10 \mathrm{IU} / \mathrm{ml}$ hCG were added to the IVM media according to the experimental design described below.

In vitro matured oocytes with expanded cumulus cells were briefly treated with hyaluronidase $(0.01 \%$ in Hepes-TL-PVP) and denuded of cumulus cells using a finely drawn glass capillary pipette. Oocytes extruding the first polar body were used for the experiments.

\section{Immunofluorescence}

Spindle MTs were immunostained according to Kim et al. [7] and Liu et al. [15]. Denuded oocytes were fixed with $3 \%$ paraformaldehyde in PBS for 90 min on ice. Subsequently, oocytes were incubated in PBS containing $0.5 \%$ Triton- $X 100$ and $30 \mathrm{mg} / \mathrm{ml}$ bovine serum albumin (BSA, Fraction V) for $20 \mathrm{~min}$ and then with anti- $\alpha$-tubulin monoclonal antibody (T-5168, 1:300 in PBS) for $90 \mathrm{~min}$. To prevent nonspecific cross reactions, oocytes were treated with blocking solution containing $0.1 \mathrm{M}$ glycine (Wako Pure Chemical, Osaka, Japan), 0.01\% TritonX100, $10 \mathrm{mg} / \mathrm{ml}$ powdered milk (Wako), $5 \mathrm{mg} / \mathrm{ml}$ BSA, $0.015 \mathrm{mM}$ sodium azide and $10 \mathrm{mg} / \mathrm{ml}$ goat serum for $60 \mathrm{~min}$. Oocytes were then incubated with FITC-labeled goat anti-mouse antibody (F4018, 1:100 in PBS) for $60 \mathrm{~min}$. Chromosomes were stained with $0.05 \mathrm{mg} / \mathrm{ml}$ propidium iodide in PBS for $60 \mathrm{~min}$. All procedures were performed at $39 \mathrm{C}$. Oocytes were mounted on glass slides and covered with anti-fading mounting media (Vectashield, Vector Lab. Burlingame, CA, USA). Meiotic spindles were examined using a confocal laser microscope (LSM-510, Carl Zeiss Inc., Jena, Germany).

\section{Measurements of spindle length and area}

Ten z-section images per oocyte were acquired to reconstruct a spindle morphology using the 

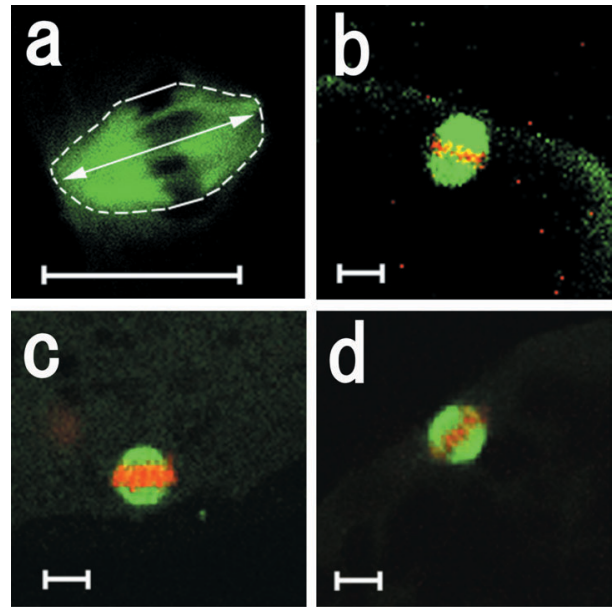

Fig. 1. Immunofluorescence images of spindles in MII oocytes matured under various conditions. Spindle length and area were measured as shown in (a). The arrow indicates the length of the spindle and the dashed line shows the area measured. The spindle in the in vivo matured oocyte is shown in (b). The spindle in IVM oocytes matured with or without hormonal supplements were shown in (c) and (d). Green: Microtubules; Red: chromosomes. Bar $=10 \mu \mathrm{m}$.

accompanying software of the LSM-510. The length (long axis) and area of each spindle were measured from reconstructed spindle images using the scale tool on the microscope (Fig. 1a).

\section{Experiment 1: Comparison between in vivo and in vitro matured oocytes}

Spindle morphology was compared between oocytes matured either in vitro or in vivo in this experiment. Cumulus-rich COCs, which had compact multiple layers of cumulus cells, were used to prepare IVM oocytes. Hormonal supplements were given for $22 \mathrm{~h}$ during the first half of maturation.

Experiment 2: Influence of amounts of cumulus cells on spindle morphology in IVM oocytes

COCs were divided into two groups based on the amount of cumulus cells. Cumulus-rich COCs were selected as described in Experiment 1, and those with a single or double layer of cumulus cells were selected as cumulus-poor COCs. IVM oocytes were produced under the same conditions as
Experiment 1, and spindle morphology was compared between these COCs groups.

Experiment 3: Effects of hormonal deprivation on spindle morphology in IVM oocytes

Spindle morphology was compared between IVM oocytes matured with or without hormonal supplements. COCs were selected as described in Experiment 1 for IVM oocyte preparation. For oocytes matured with hormonal supplements, hormones were present in media throughout the maturation process.

Experiment 4: Effects of duration of hormonal exposure on spindle morphology in IVM oocytes

Hormone supplements were given either for $22 \mathrm{~h}$ (as in Experiment 1) or $6 \mathrm{~h}$ during the first part of maturation, and spindle morphology was compared between the oocytes prepared under these conditions.

\section{Statistical analysis}

Differences between measured spindle lengths and areas were tested for significance with the Student's t-test. The level of significance was set at $\mathrm{P}<0.05$.

\section{Results}

Fig. 2 summarizes the result of comparisons for spindle length and area. When in vivo and in vitro matured oocytes were compared (Fig. 2a), the spindle length was significantly shorter in IVM oocytes $(p<0.05)$. Spindle shape in these IVM oocytes were rather round and reduced in size (Fig. $1 b$ and $c)$.

The result of comparison of spindle morphology between oocytes derived from cumulus-rich and cumulus-poor COCs is shown in Fig. 2b. Oocytes prepared from cumulus-poor COCs showed a reduction in spindle areas compared to those from cumulus-rich COCs $(p<0.05$, Fig. $2 b)$.

The effect of hormonal deprivation on spindle morphology in IVM oocytes is shown in Fig. 2c. Oocytes matured without hormones showed significant reduction in both spindle length and area compared to those matured with hormones. As shown in Fig. 1d, the MII spindle in oocytes matured without hormonal supplements had a remarkably shorter length and a round shape. 


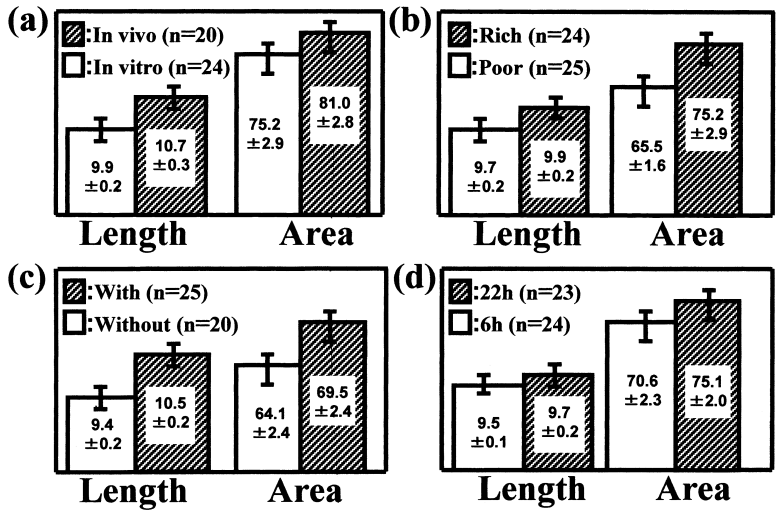

Fig. 2. Comparison of spindle morphology between oocytes matured under various conditions. (a): Spindle morphology comparison between in vivo and in vitro matured MII oocytes; (b): the influence of amounts of cumulus cells on spindle; (c): the effect of hormonal deprivation during in vitro oocyte maturation on spindle morphology; (d): the effect of changes in hormonal exposure duration on spindle morphology of IVM oocytes. Length $=\mu \mathrm{m}$, Area $=\mu \mathrm{m}^{2}$

Fig. $2 \mathrm{~d}$ shows the result of comparison of spindle morphology between oocytes matured in hormonesupplemented media for 6 and $22 \mathrm{~h}$. There was no statistical difference in spindle length and area between these two groups.

\section{Discussion}

Maturation of mammalian oocytes has two aspects: nuclear maturation and cytoplasmic maturation. Nuclear maturation refers to the completion of meiotic chromosomal division, which results in a haploid DNA content, while cytoplasmic maturation is the process in which oocytes acquire developmental competence [16]. In porcine oocytes, nuclear maturation can be efficiently induced in vitro by culturing in gonadotropin-supplemented media for about 44 hours. On the other hand, in vitro cytoplasmic maturation of porcine oocytes is very vulnerable to various factors, such as medium composition and oxidative stress [17]. For example, follicular fluid factors [18], gonadotropin [19], growth factor [20], cysteine [21], cysteamine [22] and hyaluronic acid [23] have been reported as medium components that influence cytoplasmic maturation.

Recent advancements in porcine IVM systems have successfully produced normal offspring from IVM and in vitro fertilized (IVF) oocytes [24]. NCSU23, which was used in this study, is one of the most frequently used media for porcine IVM. We have also produced a significant number of pigs from oocytes matured in NCSU23 medium using cloning technology [25] and intracytoplasmic sperm injection (Kurome et al., submitted for publication). In this study, we showed that spindle length of IVM oocytes was clearly shorter have than that of in vivo derived oocytes. This suggests that the current IVM conditions not yet reached the quality of the in vivo conditions. In fact, we found that the rate of embryonic development to blastocysts was significantly lower in artificially activated IVM oocytes than for in vivo ovulated eggs (data not shown).

Reduction in spindle length and area was similarly observed in oocytes derived from cumulus-poor COCs and in those matured without gonadotropins. We also found that in vitro developmental competence to the blastocyst stage was lower in the IVM oocytes derived from cumulus-poor COCs, when compared with those from cumulus-rich COCs (data not shown). IVM oocytes matured without gonadotropins also showed extremely compromised developmental competence to blastocysts (data not shown). On the other hand, the different durations of culture in hormone-supplemented media, 6 or 22 hours, during the first half of maturation did not affect spindle length and area. In our preliminary study, these conditions also did not influence the ability of parthenogenetic development (data not shown).

Collectively, our study showed that suboptimal maturation conditions caused significant reduction in both spindle length and area. Therefore, spindle morphology might also be a useful index for pigs that reflects the cytoplasmic quality along the course of oocyte maturation. Sunfins et al., however, has reported in mice that in vivo derived oocytes have a larger reduction in both spindle length and area than those of IVM oocytes [13]. Further studies are required to determine whether improper cytoplasmic maturation is linked to shorter and smaller spindle formation in other animals. 


\section{Acknowledgements}

This study was supported by the Program for Promotion of Basic Research Activities for Innovative Biosciences (PROBRAIN) and a
"Biotechnology Venture Research-andDevelopment Base Maintenance Enterprise" Project for Private Universities subsidy from the Ministry of Education, Culture, Sports, Science and Technology, Japan, 2002-2006.

\section{References}

1. Prather RS, Hawley RJ, Carter DB, Lai L, Greenstein JL. Transgenic swine for biomedicine and agriculture. Theriogeneology 2003; 59: 115-123.

2. Velander WH, Johnson JL, Page RL, Russell CG, Subramanian A, Wilkins TD, Gwazdauskas FC, Pittius C, Drohan WN. High-level expression of a heterologous protein in the milk of transgenic swine using the cDNA encoding human protein C. Proc Natl Acad Sci USA 1992; 89: 12003-12007.

3. Petters RM, Alexander CA, Wells KD, Collins EB, Sommer JR, Blanton MR, Rojas G, Hao Y, Flowers WL, Banin E, Cideciyan AV, Jacobson SG, Wong F. Genetically engineered large animal model for studying cone photoreceptor survival and degeneration in retinitis pigmentosa. Nat Biotechnol 1997; 15: 965-970.

4. Lai L, Kolber-Simonds D, Park KW, Cheong HT, Greenstein JL, Im GS, Samuel M, Bonk A, Rieke A, Day BN, Murphy CN, Carter DB, Hawley RJ, Prather RS. Production of alpha-1,3galactosyltransferase knockout pigs by nuclear transfer cloning. Science 2002; 295: 1089-1092.

5. Betthauser J, Forsberg E, Augenstein M, Childs L, Eilertsen K, Enos J, Forsythe T, Golueke P, Jurgella G, Koppang R, Lesmeister T, Mallon K, Mell G, Misica P, Pace M, Pfister-Genskow M, Strelchenko N, Voelker G, Watt S, Thompson S, Bishop M. Production of cloned pigs from in vitro systems. Nat Biotechnol 2000; 18: 1055-1059.

6. Nagai T, Yamauchi N, Kikuchi K. Nuclear and cytoplasmic maturation in vitro of porcine oocytes. J Reprod Dev Suppl 2001; 47: 55-62

7. Kim N-H, Funahashi H, Prather RS, Schattem G, Day BN. Microtubule and microfilament dynamics in porcine oocytes during meiotic maturation. $\mathrm{Mol}$ Reprod Dev 1996; 43: 248-255

8. Schatten G, Simerly C, Schatten H. Microtubule configurations during fertilization, mitosis, and early development in the mouse and the requirement for egg microtubule-mediated motility during mammalian fertilization. Proc Natl Acad Sci USA 1985; 82: 4152-4156

9. Eroglu A, Toth TL, Toner M. Alterations of the cytoskeleton and polyploidy induced by cryopreservation of metaphase II mouse oocytes. Fertil Steril 1998; 69: 944-957.

10. Liu L, Trimarchi JR, Oldenbourg R, Keefe DL.
Increased birefringence in the meiotic spindle provides a new marker for the onset of activation in living oocytes. Biol Reprod 2000; 63: 251-258.

11. Wang WH, Hackett RJ, Meng L, Keefe DL. Spindle observation and its relationship with fertilization after ICSI in living human oocytes. Proc 55th annual meeting of American Society for Reproductive Medicine 1999; p. S1 (Abstr).

12. Eichenlaub-Ritter U, Chandley AC, Gosden RG. Alterations to the microtubular cytoskeleton and increased disorder of chromosome alignment in spontaneously ovulated mouse oocytes aged in vivo: an immunofluorescence study. Chromosoma 1986; 94 : 337-345.

13. Sanfins A, Lee GY, Plancha CE, Overstrom EW, Albertini DF. Distinctions in meiotic spindle structure and assembly during in vitro and in vivo maturation of mouse oocytes. Biol Reprod 2003; 69: 2059-2067.

14. Petters RM, Wells KD. Culture of pig embryos. J Reprod Fertil Suppl 1993; 48: 61-73.

15. Liu RH, Sun QY, Li YH, Jiao LH, Wang WH. Effects of cooling on meiotic spindle structure and chromosome alignment within in vitro matured porcine oocytes. Mol Reprod Dev 2003; 65: 212-218.

16. Moor RM, Mattioli M, Ding J, Nagai T. Maturation of pig oocytes in vivo and in vitro. J Reprod Fertil Suppl 1990; 40: 197-210.

17. Funahashi H, Day BN. Advances in in vitro production of pig embryos. I Reprod Fertil Suppl 1997; 52: 271-283.

18. Niwa K. Effectiveness of in vitro maturation and in vitro fertilization techniques in pigs. J Reprod Fertil Suppl 1993; 48: 49-59.

19. Liu L, Dai Y, Moor RM. Role of secreted proteins and gonadotrophins in promoting full maturation of porcine oocytes in vitro. Mol Reprod Dev 1997; 47: 191-199.

20. Ding J, Foxcroft GR. Epidermal growth factor enhances oocyte maturation in pigs. Mol Reprod Dev 1994; 39: 30-40.

21. Yoshida M. Role of glutathione in the maturation and fertilization of pig oocytes in vitro. Mol Reprod Dev 1993; 35: 76-81.

22. Grupen CG, Nagashima H, Nottle MB. Cysteamine enhances in vitro development of porcine oocytes matured and fertilized in vitro. Biol Reprod 1995; 53: 
173-178.

23. Miyoshi K, Umezu M, Sato E. Effect of hyaluronic acid on the development of porcine 1-cell embryos produced by a conventional or new in vitro maturation/fertilization system. Theriogenology 1999; 51: 777-784.

24. Mattioli M, Bacci G, Seren E. Developmental competence of pig oocytes matured and fertilized in vitro. Theriogenology 1989; 31: 1201-1207.

25. Fujimura T, Kurome M, Murakami H, Takahagi $Y$, Matsunami K, Shimanuki S, Suzuki K, Miyagawa $\mathbf{S}$, Shirakura $\mathbf{R}$, Nagashima $\mathbf{H}$. Cloning of the transgenic pigs expressing human decay accelerating factor and Nacetylglucosaminyltransferase III. Cloning stem cells 2004; 6: 294-301. 